\title{
Burden of surgical site infection following cesarean section in sub-Saharan Africa: a narrative review
}

This article was published in the following Dove Medical Press journal:

International Journal of Women's Health

\section{Angie Sway' \\ Peter Nthumba ${ }^{2}$ \\ Joseph Solomkin ${ }^{3}$ \\ Giorgio Tarchini ${ }^{4}$ \\ Ronald Gibbs ${ }^{5}$ \\ Yanhan $\operatorname{Ren}^{6}$ \\ Anthony Wanyoro ${ }^{7}$}

'Medical Writing, World Surgical Infection Society, Cincinnati, OH, USA;

${ }^{2}$ Plastic, Reconstructive and Hand Surgery, AIC Kijabe Hospital, Kijabe, Kenya; ${ }^{3}$ Department of Surgery,

University of Cincinnati College of Medicine, Cincinnati, OH, USA;

${ }^{4}$ Department of Infectious Disease, Cleveland Clinic Florida, Weston, FL, USA; ${ }^{5}$ Department of Obstetrics and Gynecology, University of Colorado Hospital, Denver, CO, USA; ${ }^{6}$ Research and Implementation, World Surgical Infection Society, Cincinnati, $\mathrm{OH}$, USA; ${ }^{7}$ Department of Obstetrics and Gynecology, School of Medicine, Kenyatta University, Nairobi, Kenya
Correspondence: Angie Sway World Surgical Infection Society, 7800 Cooper Road - suite 207, Cincinnati, Ohio 45242, USA

Tel +I 5622879199

Email asway@worldsis.org

\begin{abstract}
Cesarean section (CS) is the most common operative procedure performed in sub-Saharan Africa (SSA), accounting for as much as $80 \%$ of the surgical workload. In contrast to CSs performed in high-income countries, CSs performed in SSA are accompanied by high morbidity and mortality rates. This operation is the most important known variable associated with an increased probability of postpartum bacterial infection. The objective of this review was to assess surgical outcomes related to CS in SSA. PubMed (including Medline), CINAHL, Embase, and the World Health Organization's Global Health Library were searched without date or language restrictions. A total of 26 studies reporting surgical site-infection rates after CS were identified, representing 14,063 women from 14 countries. The vast majority $(76.7 \%)$ of CSs performed were emergency operations. The overall CS rate for women included in this review was $12.4 \%$ (range: $1.0 \%-41.9 \%$ ). Only 17 of 26 total studies reported a significant proportion of women receiving antimicrobials of any kind. The surgical site-infection rate was $15.6 \%$ and the wound-infection rate $10.3 \%$.
\end{abstract}

Keywords: cesarean section, maternal mortality, surgical site infection, wound infection, sepsis, sub-Saharan Africa

\section{Introduction}

The $45 \%$ decline in global maternal deaths from 1990 to $2013^{1}$ is a deceptively rosy statistic that obscures the vast discrepancy between current morbidity and mortality rates in high- and low- to middle-income countries. The maternal mortality ratio in developing regions of the world is 14 times greater than in developed regions, and countries in sub-Saharan Africa (SSA) remain the most gravely impacted. ${ }^{1}$ Therefore, maternal and neonatal health remains a crucial field of concern in global health, particularly because the elevated incidence of maternal morbidity and mortality in low- and middle-income countries is largely preventable. ${ }^{1}$

Cesarean section (CS) delivery is one of the most common operative procedures performed in SSA, accounting for as much as $80 \%$ of the surgical workload. ${ }^{2,3}$ In contrast to CS performed in high-income countries, CSs performed in SSA are primarily emergency operations and accompanied by high morbidity and mortality rates. ${ }^{4}$ This operation is the most important known variable associated with an increased probability of postpartum bacterial infection when compared with vaginal birth, with reported rates of infection ranging from $1 \%$ to $25 \%$, about 5 to 20 times higher than that of vaginal delivery. ${ }^{5}$ In addition to the physical consequences associated with postpartum bacterial infection, such as maternal infirmity and neonatal mortality, these infections often share a common pathophysiological pathway with fetal and neonatal infections and death, thereby contributing to the significant social costs stemming from maternal illness. 
Surgical site infections (SSIs) are an important global cause of morbidity and mortality in patients undergoing all types of operations. These infections lead to increased duration of hospitalization, health care costs, morbidity, and risk of death. Recent systematic reviews from the World Health Organization (WHO) have highlighted particularly high SSI rates in SSA..${ }^{67}$ However, since these rates are derived from a mix of operative procedures, the true rate of SSI following CS is not clear, but is likely greater.

$\mathrm{CS}$ is of particular interest as an index procedure for SSI modeling and assessment of interventions because many of the complicating factors that may obscure the true cause of infection are not present: the surgical technique is standardized and the operation generally performed on younger women who do not suffer from the disease- and agerelated risks of infection and comorbidities seen in broader surgical surveys.

The objective of this review is to create a picture of recent surgical outcomes related to CS in SSA. While there have been single- and multiple-country studies on maternal health for this region, there has been no attempt to synthesize the information across all of the countries in SSA. This kind of region- and procedure-specific information may allow for more precise design and implementation of guidelines being developed for maternal sepsis and prevention of postCS SSIs, and can then be used by policymakers, hospital administrators, and health care workers to identify areas for improvement.

\section{Methods}

We conducted a review of studies on the incidence and epidemiology of SSI following CS in SSA. PubMed (including Medline), CINAHL, Embase, and the WHO's Global Health Library were searched using the terms: ("surgical wound infection" [MeSH] OR surgical site infection* [TIAB] OR "SSI" OR "SSIs" OR surgical wound infection* [TIAB] OR surgical infection* [TIAB] OR post-operative wound infection* [TIAB] OR postoperative wound infection* [TIAB] OR wound infection* [TIAB] OR (("preoperative care" [MeSH] OR "preoperative care" OR "pre-operative care" OR "perioperative care" [MeSH] OR "perioperative care" OR "peri-operative care" OR perioperative OR intraoperative OR "perioperative period" [MeSH] OR "intraoperative period" [MeSH]) AND ("infection" [MeSH] OR infection [TIAB] $)))$ AND (((()((((“cesarean childbirth”) OR “cesarean complications") OR "cesarean delivery complications") OR "cesarean infections") OR cesarean) OR cesarean)) AND (("surgical wound infection" [MeSH] OR surgical site infection* [TIAB] OR "SSI" OR "SSIs" OR surgical wound infection* [TIAB] OR surgical infection* [TIAB] OR post-operative wound infection* [TIAB] OR postoperative wound infection* [TIAB] OR wound infection* [TIAB] OR (("preoperative care" [MeSH] OR "preoperative care" OR "pre-operative care" OR "Perioperative Care" [MeSH] OR "perioperative care" OR "peri-operative care" OR perioperative OR intraoperative OR "perioperative period" $[\mathrm{MeSH}] \mathrm{OR}$ "intraoperative period" $[\mathrm{MeSH}]$ ) AND ("infection" [MeSH] OR infection [TIAB])))))) AND ("Africa south of the Sahara" OR "sub Saharan Africa").

This search was also completed separately with individual names of countries in SSA specified by the Library of Congress. We applied the same search strategy to the Cochrane database to identify any published reviews and included references. No date restrictions were used in the search. Prospective, randomized trials were excluded, in order to eliminate studies with eligibility criteria that excluded women with conditions considered to be risk factors for SSI, as this might have confounded our analyses. References from the eligible studies were reviewed to identify additional studies.

All results from the search were independently screened, reviewed, and analyzed. Two research associates performed three levels of screening: title, abstract, and full text. Full-text articles of relevant studies were obtained and analyzed for content. Extracted data included authors, year of publication, country or countries where the study was done, study period, study setting, study population size, indications for $\mathrm{CS}$, potential risk factors, reported infection prevalence or cumulative incidence data, wound-contamination class and type of SSI, antibiotic prophylaxis, and microbial isolates (if studied). Institutional review board approval was not necessary, as this was a review of previously published studies, all of which had obtained approval.

\section{Quality assessment}

To allow comparisons between individual studies, evaluate the quality of conclusions drawn from individual studies, and identify reporting gaps, we created a quality-scoring system for this review, modified from others of similar utility. ${ }^{8,9}$ The system we developed awarded one point for the reporting of each of the ten factors: study type, study dates, description of study site, HIV status, antiretroviral therapy status, preeclampsia/hypertension, antenatal care status, rupture of membranes, meconium staining, and chorioamnionitis. The same scoring system was used for the reporting of 15 operative and outcome variables: repeat CS, emergency or elective operation, cephalopelvic disproportion (CPD) or obstructed 
labor, fetal distress, hemorrhage, breech, type of antibiotic administered, timing of antibiotic administration, duration of operation, length of stay, Centers for Disease Control and Prevention (CDC) SSI type, endometritis, maternal death, fetal death, and duration of follow-up. The total number of categories was thus 25. As such, the rating for each could range from 0 (lowest quality) to 25 points (highest quality).

Where similar scoring systems have used categories chosen to evaluate the quality of study management and performance, our modified system is focused on evaluating how widely certain factors were reported. Investigators chose the included categories for their importance in understanding factors contributing to SSI: certain patient and operational variables are well known to increase the risk of infection, and certain definitional categories are useful in understanding the type of infection encountered. ${ }^{12,13}$ We believe that these categories outline the minimum information needed to clearly define the circumstances surrounding and leading to SSI.

\section{Results}

A total of 26 studies $^{10-35}$ reporting SSI rates after CS were included in this review, representing procedures conducted on 14,063 women from 14 countries in SSA. Table 1 outlines the general characteristics of the eligible studies. In sum, 22 of these studies were conducted at academic and/or urban hospitals, the majority of which served as urban referral centers for smaller health care facilities. The mean city population for the hospitals was 2,376,486 with a range of 7,966-16,060,303. All eligible studies were observational. Quality scores for each study are also shown in this table. Scores ranged from 4 to 16 of a maximum of 25. Almost all studies reported the study type, study dates, and type of facility. Repeat CS, emergency or elective surgery, CPD and/or obstructed labor, and fetal distress were the most widely reported categories.

Table 2 shows background demographic information for the included studies and hospitals. The vast majority (76.7\%) of CSs performed were emergency operations. The lowest rate of emergency CSs was $26.7 \%$ and the highest $100.0 \%$. It was also reported that many of the hospitals saw a high number of births per year (mean 16,752, range 274-174,561), as well as a high ratio of CSs to vaginal births. The overall $\mathrm{CS}$ rate for women included in this review was $12.4 \%$ with a range of $1.0 \%-1.9 \%$.

As shown in Table 3, the most significant indication for $\mathrm{CS}$ in this population was CPD and/or obstructed labor (40.4\%), followed by repeat CS $(19.6 \%)$, fetal distress $(13.0 \%)$, prolonged rupture of membranes $(7.7 \%)$, breech and/or malpresentation (7.7\%), eclampsia (6.6\%), hemorrhage $(6.3 \%)$, and cord prolapse (3.7\%). CPD is likely accompanied by prolonged ruptured amniotic membranes and thus becomes a marker for contaminated procedures. Prevalence ranged $8.1 \%-76.9 \%$ in CPD/obstructed labor, $6.4 \%-44.4 \%$ for repeat CS, $2.9 \%-36.1 \%$ in fetal distress, $0.7 \%-64.9 \%$ in prolonged rupture of membranes, $3.0 \%-13.1 \%$ in breech and/or malpresentation, $0.6 \%-18.8 \%$ in preeclampsia/hypertension, $1.4 \%$ $14.4 \%$ in hemorrhage, and $1.4 \%-17.5 \%$ in cord prolapse.

Table 4 details the administration of antibiotics, widely considered a key strategy for the prevention of SSI. Only 17 of 26 total studies reported a significant proportion of women receiving antimicrobials of any kind, and only eleven studies of those 17 reported the exact antibiotic or combination of antibiotics used. There was no uniformity in either the medication given or the timing (preoperative vs postoperative) across the studies.

Table 5 shows the reported infectious complications categorized by definitions of infection used by the authors. Seven studies reported infection data based on standardized terminology given by the CDC. The SSI rate for these studies was $15.6 \%$. The most widely reported SSI category, wound infection, had a cumulative incidence of $10.3 \%$.

\section{Discussion}

Efforts to reduce maternal mortality and morbidity must focus not only on expanding the quantity and availability of care but also on improving the quality of existing health care. In order to move forward with the second goal, there must be clear and accurate understanding of the current quality of care. Singlecenter audits are of considerable importance for both the local population and the larger population, because they can suggest improvements in reporting standards and quality of care. Given the high rates of infection, it is vital to understand past and current experiences in local health care centers in order to tailor a solution built on a foundation of good evidence. Reviews that synthesize the entire field of information are a powerful tool that can illuminate key areas for high-impact intervention and the data gaps that should be addressed. ${ }^{8,36}$

The purpose of this review was to provide information on reported infection rates following CS in SSA. We found rates of infection ranging from $10.3 \%$ to $15.6 \%$, many times greater than those in high-income countries, such as the US. Furthermore, the duration of follow-up was $<30$ days in at least three studies, suggesting that SSI rates may have been underreported. This review also reinforced the notion that nearly all CSs in SSA are performed as emergency operations. 


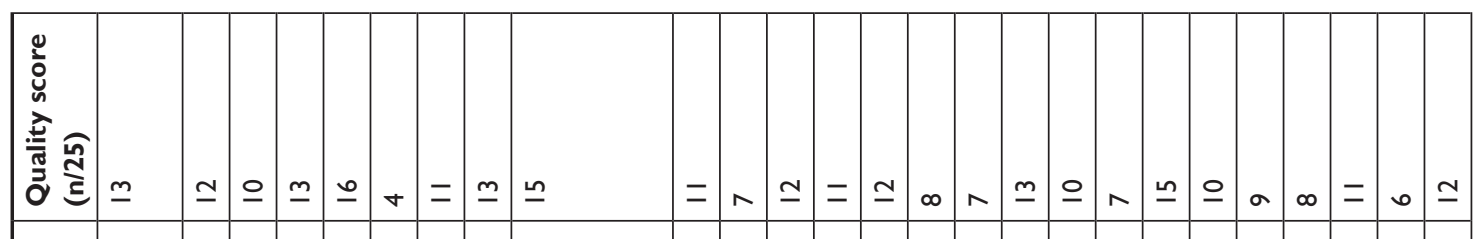

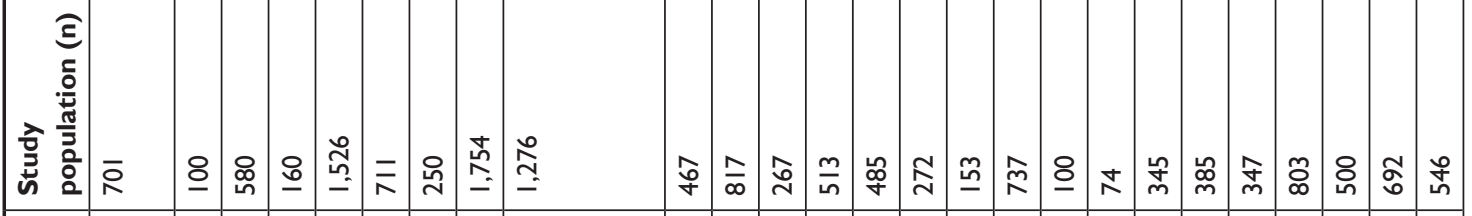

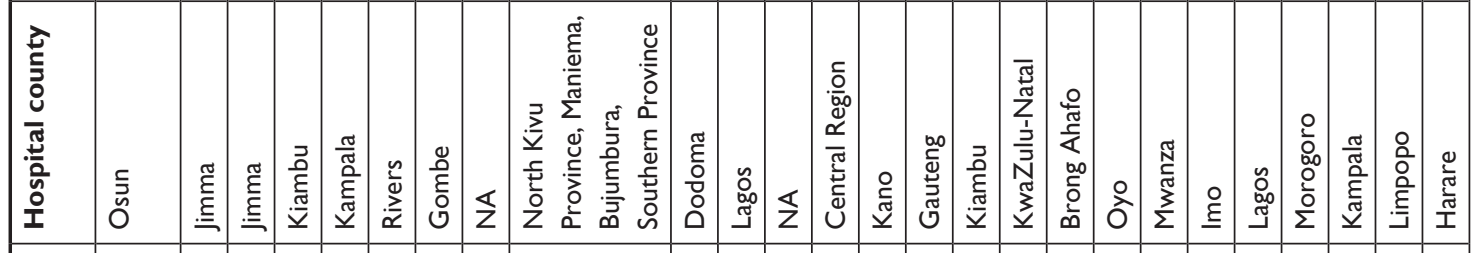

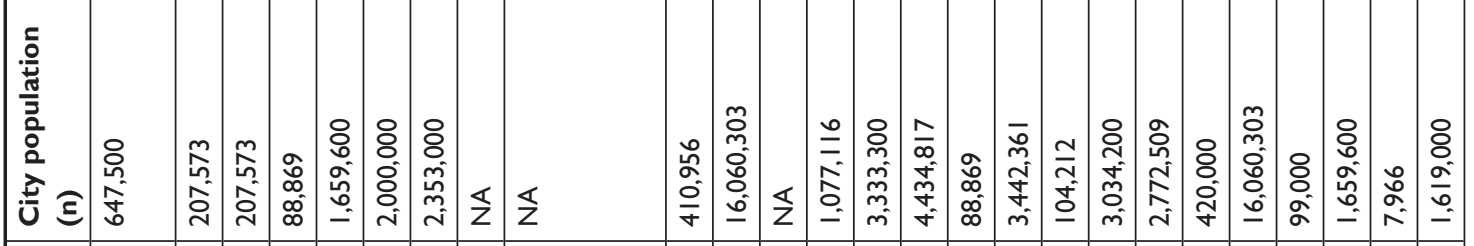

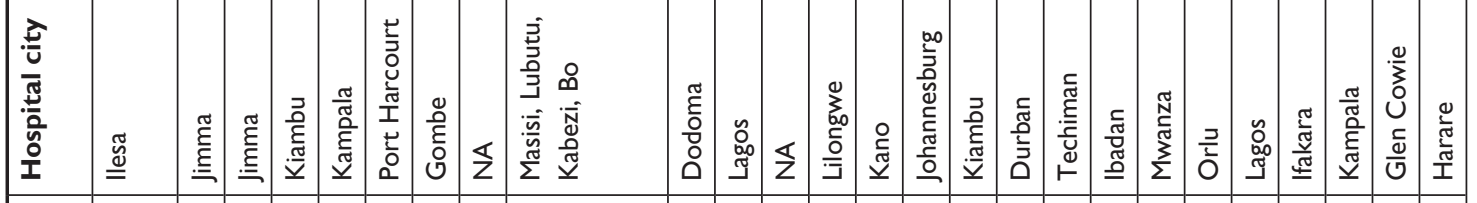

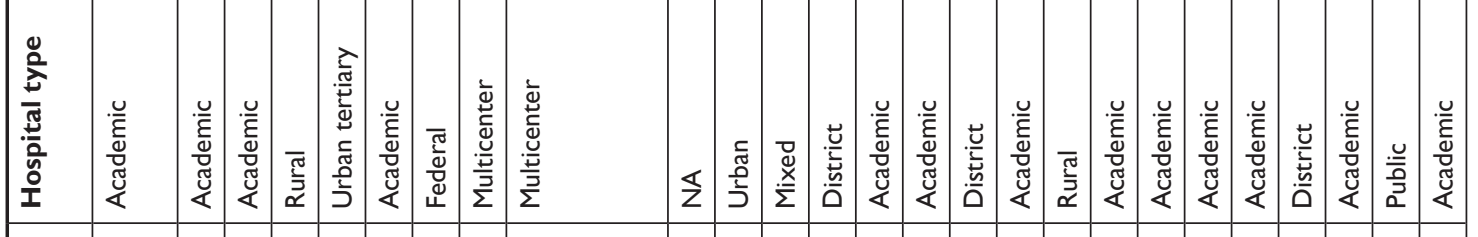

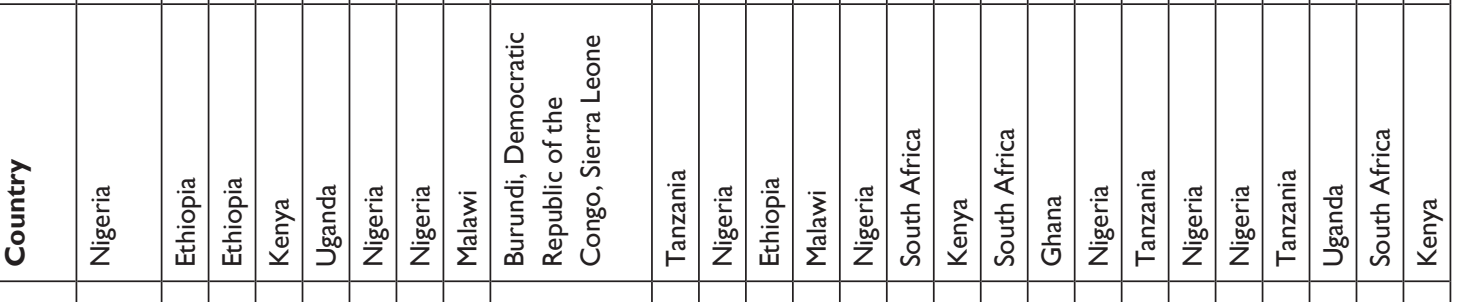

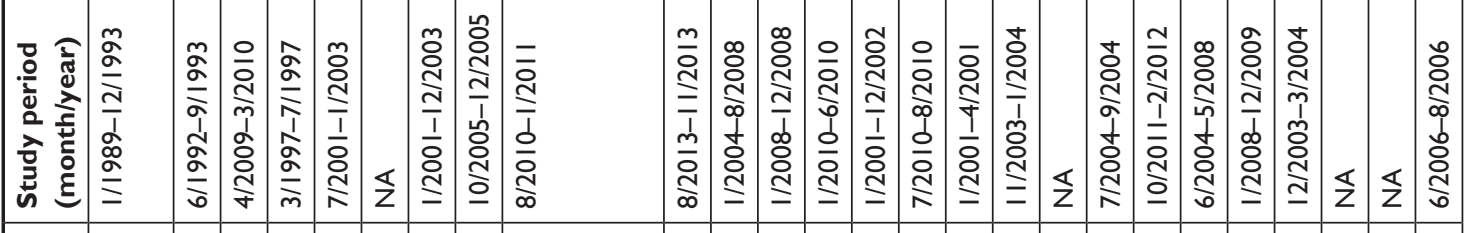

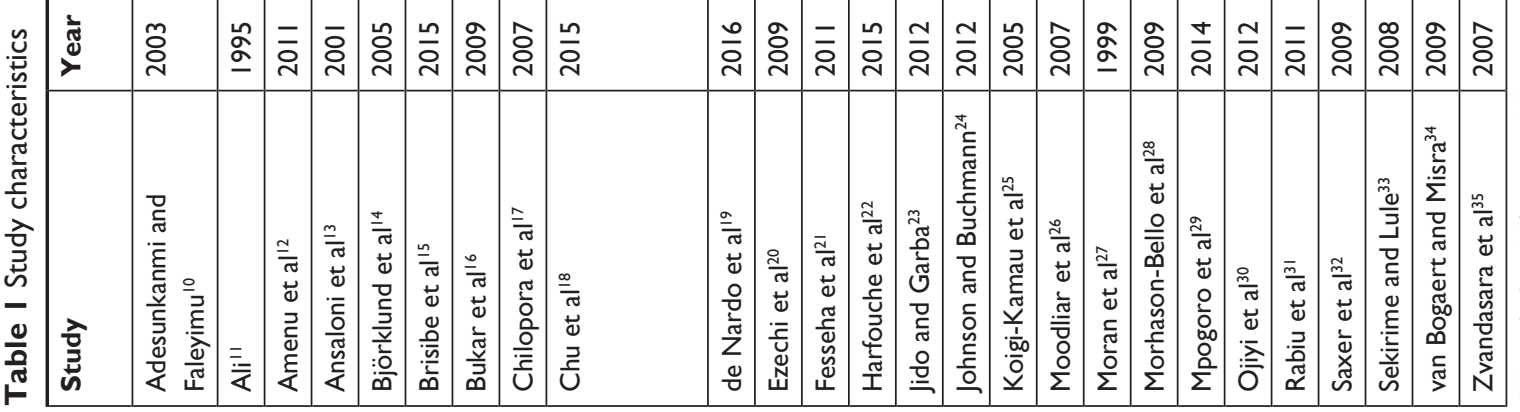


Table 2 Background

\begin{tabular}{|c|c|c|c|c|c|}
\hline Study & $\begin{array}{l}\text { Hospital births per } \\
\text { year, } n\end{array}$ & $\begin{array}{l}\text { Hospital cesareans } \\
\text { per year, } n \text { (\% of total } \\
\text { births) }\end{array}$ & Elective, n (\%) & Emergency, n (\%) & HIV $^{+}, \mathrm{n}(\%)$ \\
\hline Adesunkanmi and Faleyimu ${ }^{10}$ & NA & NA & $86(12.3)$ & $615(87.7)$ & NA \\
\hline Ali" $^{\prime \prime}$ & 1,236 & $100(8.1)$ & $8(8.0)$ & $92(91.6)$ & NA \\
\hline Amenu et $\mathrm{al}^{12}$ & NA & NA & $23(4.0)$ & $557(96.0)$ & NA \\
\hline Ansaloni et al $^{13}$ & 3,072 & $242(7.9)$ & $76(47.5)$ & $84(52.5)$ & NA \\
\hline Björklund et al ${ }^{14}$ & 27,000 & $5,400(20.0)$ & $34(2.2)$ & I,492 (97.8) & $96(6.3)$ \\
\hline Brisibe et al ${ }^{15}$ & NA & NA & NA & NA & NA \\
\hline Bukar et $\mathrm{al}^{16}$ & 724 & $88(12.2)$ & $69(27.6)$ & $180(72.0)$ & NA \\
\hline Chilopora et al ${ }^{17}$ & NA & NA & $452(25.8)$ & I,302 (74.4) & NA \\
\hline Chu et al ${ }^{18}$ & NA & NA & $47(3.7)$ & I,229 (96.3) & NA \\
\hline de Nardo et al ${ }^{19}$ & NA & NA & $42(9.0)$ & $425(91.0)$ & NA \\
\hline Ezechi et $\mathrm{al}^{20}$ & NA & NA & $599(73.3)$ & $218(26.7)$ & NA \\
\hline Fesseha et $\mathrm{a}^{21}$ & $|74,56|$ & $17,145(9.8)$ & $56(21.0)$ & $205(76.8)$ & NA \\
\hline Harfouche et $\mathrm{a}^{22}$ & 14,780 & $2,052(13.9)$ & 0 & $513(100)$ & $76(14.8)$ \\
\hline Jido and Garba ${ }^{23}$ & 3,162 & $320(10.1)$ & $51(10.5)$ & $434(89.5)$ & NA \\
\hline Johnson and Buchmann ${ }^{24}$ & NA & NA & $53(19.5)$ & $219(80.5)$ & NA \\
\hline Koigi-Kamau et $\mathrm{al}^{25}$ & 7,892 & $612(7.8)$ & II (7.2) & $14 \mid(92.2)$ & $13(8.5)$ \\
\hline Moodliar et $\mathrm{al}^{26}$ & 2,126 & $744(35.0)$ & $112(15.2)$ & $625(84.8)$ & NA \\
\hline Moran et $\mathrm{al}^{27}$ & 10,000 & $100(1.0)$ & 0 & $100(100)$ & NA \\
\hline Morhason-Bello et a ${ }^{28}$ & 1,024 & $296(28.9)$ & $13(17.6)$ & $61(82.4)$ & NA \\
\hline Mpogoro et $\mathrm{al}^{29}$ & 2,444 & $559(22.9)$ & $26(7.5)$ & $319(92.5)$ & NA \\
\hline Ojiyi et al ${ }^{30}$ & 274 & $91(33.2)$ & $166(46.4)$ & $192(53.6)$ & NA \\
\hline Rabiu et a $\left.\right|^{31}$ & 3,569 & I,53I (42.9) & NA & NA & NA \\
\hline Saxer et a ${ }^{32}$ & NA & NA & $35(10.5)$ & $297(89.5)$ & NA \\
\hline Sekirime and Lule $^{33}$ & NA & NA & 0 & $500(100)$ & NA \\
\hline van Bogaert and Misra ${ }^{34}$ & 4,800 & $864(18.0)$ & $189(27.3)$ & $503(72.7)$ & NA \\
\hline Zvandasara et $\mathrm{al}^{35}$ & II,377 & 2,297 (20.2) & $130(23.8)$ & $4 \mid 4(75.8)$ & NA \\
\hline
\end{tabular}

Abbreviation: NA, not available.

Our review also found CS rates of $1 \%-42.9 \%$, outstripping the WHO recommendation for the optimal rate of CS, which ranges from $5 \%$ to $15 \%$ of total births. ${ }^{37,38} \mathrm{CS}$ rates have been increasing globally, ${ }^{38}$ suggesting that the population at risk of SSI following CS in SSA will grow. In the developing world, Africa has seen the fastest pace of urban growth per year for the last 20 years $(3.5 \%)$, and this rate is projected to hold steady until at least 2050 . SSA is also projected to experience a faster-than-average rate of urbanization, growing from $40 \%$ of the population living in urban areas in 2014 to $56 \%$ by $2050 .{ }^{39}$ Because the facilities that offer and perform CSs are predominantly located in urban areas, they will likely have to contend with the rise in the population served. Structural and resource-based barriers to high-quality maternal health care will become more pronounced and more damaging without timely and effective intervention. Other factors that may lead to an increase in
CS rates are increases in the number of theater facilities, increases in the number of surgeons, increased monitoring of labor, and the shifting trend from home deliveries to hospital deliveries.

\section{Limitations of data}

A few limiting factors were encountered while conducting this review, most of which stemmed from limitations in individual studies. We could not capture studies or audits that were not published and/or archived, because our search was confined to databases of published studies. Internal facility reviews or audits done in smaller or more rural health care centers may not have been accessed if they were not published or uploaded to an electronic database. Additionally, the studies included in this review were nearly all from large centers located in urban areas, which likely have access to greater resources than smaller and more rural facilities. Our data thus 


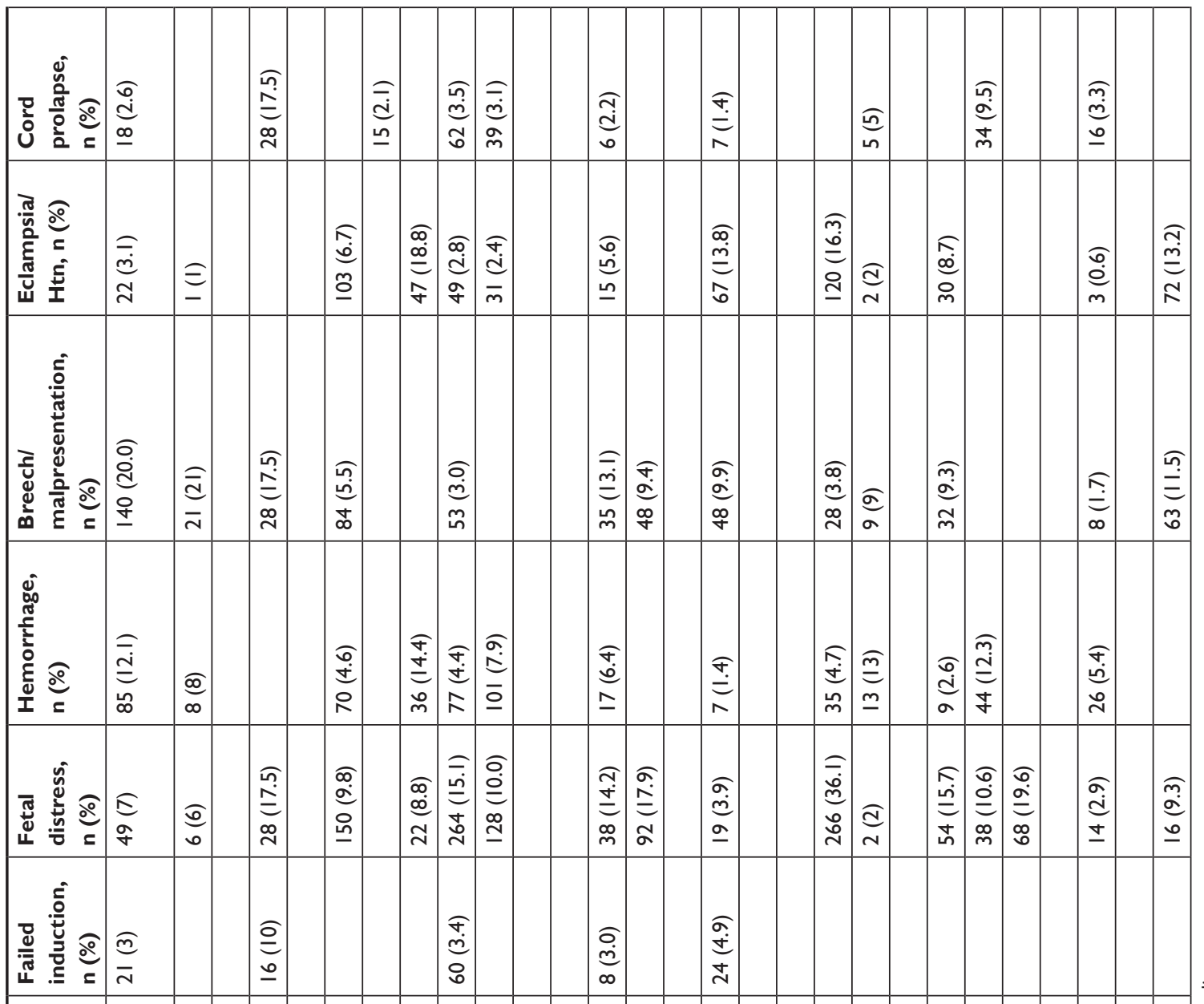

产

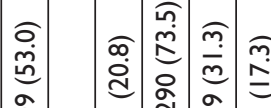

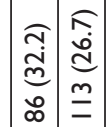

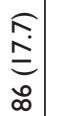

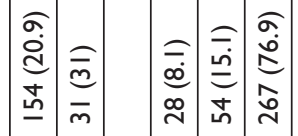

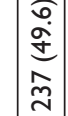

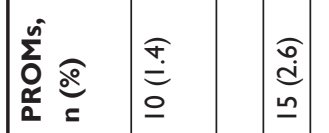

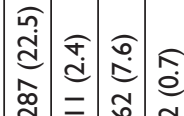

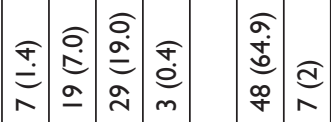

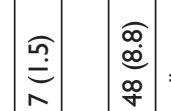

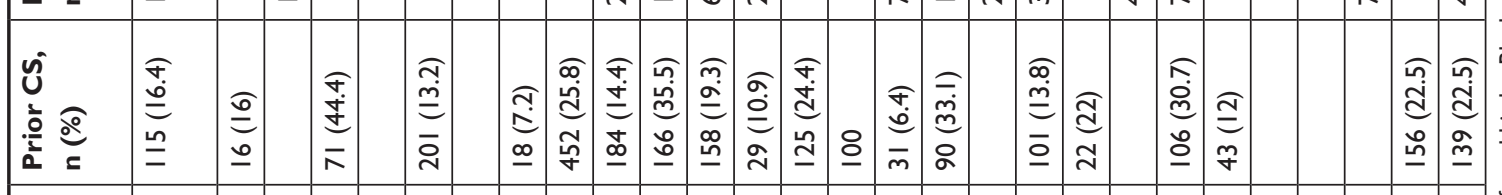

竞

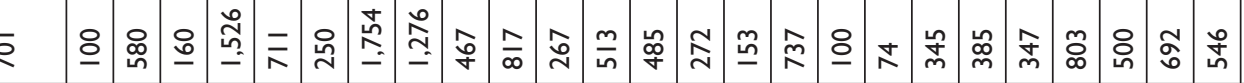

ò



西

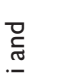

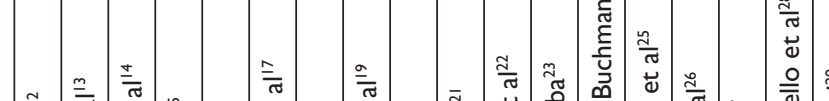

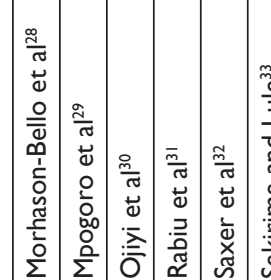

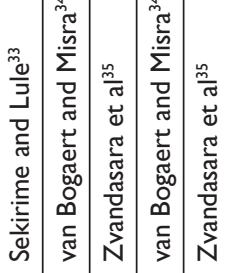

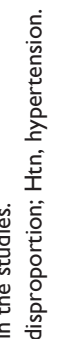

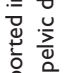

要

营 过 
Table 4 Perioperative factors

\begin{tabular}{|c|c|c|c|}
\hline Study & Patients receiving antibiotics, $\mathbf{n}(\%)$ & Antibiotic(s) used & Timing of antibiotics \\
\hline Adesunkanmi and Faleyimu ${ }^{10}$ & NA & NA & NA \\
\hline$A^{\prime i}{ }^{\prime \prime}$ & Most operated cases & NA & NA \\
\hline Amenu et $\mathrm{al}^{12}$ & NA & NA & NA \\
\hline Ansaloni et $\mathrm{al}^{13}$ & $160(100.0)$ & $\begin{array}{l}\text { Single-dose ampicillin } 3 \mathrm{~g}- \\
\text { metronidazole } 500 \mathrm{mg} \text { IV }\end{array}$ & Immediately before operation \\
\hline Björklund et al' ${ }^{14}$ & $\mathrm{I}, 495(98.0)$ & Benzyl penicillin G & $\begin{array}{l}\text { Preoperative, n (\%): } 346(22.7) \\
\text { Postoperative, n (\%): I, I } 149 \text { (75.3) }\end{array}$ \\
\hline Brisibe et al $\left.\right|^{15}$ & 0 & None & None \\
\hline Bukar et $\mathrm{al}^{16}$ & $250(100.0)$ & NA & NA \\
\hline Chilopora et al ${ }^{17}$ & $\mathrm{I}, \mathrm{I} 40(65.0)$ & NA & Preoperative \\
\hline Chu et al ${ }^{18}$ & $1,276(100.0)$ & Cefazolin I g & Preoperative \\
\hline de Nardo et al ${ }^{19}$ & $460(99.0)$ & $\begin{array}{l}\text { Ceftriaxone-metronidazole }+ \\
\text { ampicillin-cloxacillin }\end{array}$ & $\begin{array}{l}\text { Preoperative, n: } 10 \\
\text { Postoperative, n: } 450\end{array}$ \\
\hline Ezechi et $\mathrm{al}^{20}$ & NA & NA & NA \\
\hline Fesseha et $\mathrm{al}^{21}$ & $25 \mathrm{I}(94.0)$ & NA & NA \\
\hline Harfouche et $\mathrm{a}^{22}$ & $424(82.6)$ & $\begin{array}{l}\text { Chloramphenicol or penicillin or } \\
\text { ceftriaxone }\end{array}$ & NA \\
\hline Jido and Garba ${ }^{23}$ & NA & NA & NA \\
\hline Johnson and Buchmann ${ }^{24}$ & NA & NA & NA \\
\hline Koigi-Kamau et a ${ }^{25}$ & NA & NA & NA \\
\hline Moodliar et $\mathrm{al}^{26}$ & $725(98.0)$ & NA & NA \\
\hline Moran et $\mathrm{al}^{27}$ & NA & NA & NA \\
\hline Morhason-Bello et $\mathrm{a}^{28}$ & $74(100.0)$ & NA & NA \\
\hline Mpogoro et $\mathrm{al}^{29}$ & $344(99.7)$ & $\begin{array}{l}\text { Single-dose ampicillin or } \\
\text { nonampicillin combination }\end{array}$ & NA \\
\hline Ojiyi et al ${ }^{30}$ & $358(100.0)$ & $\begin{array}{l}\text { Ampicillin-cloxacillin or } \\
\text { metronidazole-gentamicin }\end{array}$ & Preoperative \\
\hline Rabiu et $a^{31}$ & NA & NA & NA \\
\hline Saxer et a $\left.\right|^{32}$ & $524(99.0)$ & $\begin{array}{l}\text { Chloramphenicol, aminopenicillin, } \\
\text { benzylpenicillin }\end{array}$ & $\begin{array}{l}\text { Preoperative, n (\%): } 63 \text { (12.0) } \\
\text { Postoperative, n (\%): } 46 \text { I (88.0) }\end{array}$ \\
\hline Sekirime and Lule $^{33}$ & $478(100.0)$ & Penicillin & Postoperative \\
\hline van Bogaert and Misra ${ }^{34}$ & $692(100.0)$ & Ceftriaxone I g IV & Post-cord clamping \\
\hline Zvandasara et $\mathrm{a}^{35}$ & $546(100.0)$ & Penicillin-chloramphenicol & Preoperative \\
\hline
\end{tabular}

Note: Values in parentheses show percentage of total births.

Abbreviation: NA, not available.

cannot be said to be representative of the process of care or SSI rates seen at rural or smaller facilities.

A major limitation was the lack of standardized reporting across the included studies. None of the studies used identical reporting forms, and few used standard definitions for indications and infectious complication, such as SSI, endometritis, or chorioamnionitis. Seven of 26 stated that the CDC criteria for SSI were used, 18 studies used the term "wound infection" often without a specific definition, and one designated "sepsis" to describe post-CS SSI. Without corresponding diagnostic definitions, it is difficult to compare the results of individual studies. Finally, the low number of studies found was in itself a limitation, particularly given the broad search parameters. Only 26 studies representing 14 countries from a total of 52 countries in SSA were found, indicating a need for more extensive reporting.

\section{Recommendations}

One category of concern highlighted by the results of this review is a relatively clear-cut and cost-effective measure: the proper administration of antibiotics. The effectiveness of antibiotic prophylaxis when administered 120 minutes or less before skin incision is established and very widely accepted. ${ }^{40}$ Broad acceptance of the use of antibiotics is reinforced by the results of this review, but there was a wide range at the time of administration, when reported. With strong evidence 


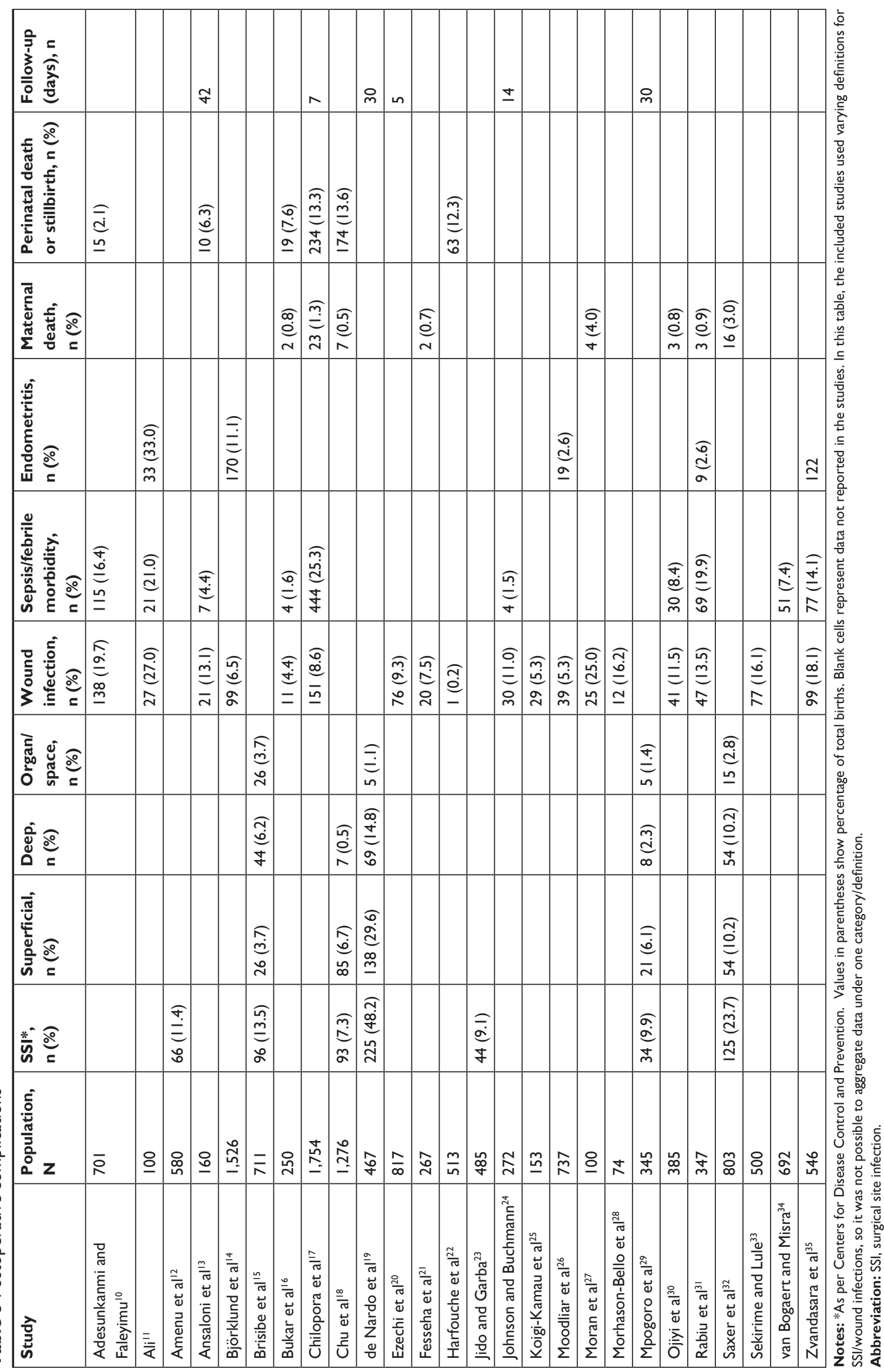


suggesting that the efficacy of antibiotics drops off sharply when not given within this interval, there must be a focus on the surveillance, education, and enforcement of this policy.

A second recommendation would be for authors to use standardized definitions when reporting SSI risk factors and SSI types. The unusually wide variance found within such categories as CPD/obstructed labor and PROMs suggest that the study investigators used differing definitions or classifications, which makes it difficult to compile comparable data. Regional journals can also assist by ensuring that authors uphold standard definitions where such definitions exist, such as in the SSI field.

There has been extensive reporting that a prolonged period from onset of labor to CS is a major avoidable factor contributing to maternal and neonatal morbidity and mortality. ${ }^{41}$ This delay can be broken into intervals, such as patient delay, transport delay, delay in care on admission to health care facility, and delayed operative delivery. Some factors contributing to delay are caused by cultural factors or lack of infrastructure, and will take greater time and resources to address. However, more short-term efforts may be focused on operative delays within facilities that are caused by the absence of a considered decision-making process. The current audit standard used is 30 minutes from decision to delivery in nonelective $\mathrm{CS}$; however, it is unclear whether crossing this threshold truly represents a significant rise in the threat of maternal and fetal complications. Our third recommendation would be for quantitative and qualitative data on timing and factors contributing to delay to be a standard part of future studies. Finding the most feasible and reasonable decision to incision time for the SSA region would contribute greatly to improving quality of care and reduce the costs of this delay to women and facilities.

The practical method we would most recommend is the criterion-based audit, which provide a logical framework for quality improvement by systematically measuring and assessing clinical practices against previously established and accepted criteria. Criterion-based audits establish region-specific criteria for good-quality care by performing systematic literature reviews, the results of which are assessed by a panel of regional and international experts to arrive at the final audit criteria. These criteria are used to determine current practices and innovate mechanisms to achieve quality improvement. The feasibility and effectiveness of criterion-based audits in developing countries has been shown, ${ }^{42}$ and we believe that this will be an important tool in the improvement of health care and standardized reporting.

\section{Conclusion}

This review of surgical site infections following cesarean section in sub-Saharan Africa found an surgical site-infection rate of $15.6 \%$ and a wound-infection rate of $10.3 \%$.

\section{Acknowledgments}

The authors would like to thank Benedetta Allegranzi, Stacey Gomes, and Katrina Kraft for their time, guidance, and contributions to this manuscript. An abstract of this paper was presented at the 27th European Congress of Clinical Microbiology and Infectious Diseases as a poster presentation with interim findings. The poster's abstract has been published by the European Society of Clinical Microbiology and Infectious Diseases. ${ }^{43}$

\section{Disclosure}

The authors report no conflicts of interest in this work.

\section{References}

1. Alkema L, Chou D, Hogan D, et al. Global, regional, and national levels and trends in maternal mortality between 1990 and 2015, with scenario-based projections to 2030: a systematic analysis by the UN maternal mortality estimation inter-agency group. Lancet. 2016;387(10017):462-474.

2. Aiken AM, Wanyoro AK, Mwangi J, Juma F, Mugoya IK, Scott JA. Changing use of surgical antibiotic prophylaxis in Thika Hospital, Kenya: a quality improvement intervention with an interrupted time series design. PLoS One. 2013;8(11):e78942.

3. Bjerring AW, Lier ME, Rød SM, et al. Assessing cesarean section and inguinal hernia repair as proxy indicators of the total number of surgeries performed in Sierra Leone in 2012. Surgery. 2015;157(5):836-842.

4. Nordberg EM. Incidence and estimated need of caesarean section, inguinal hernia repair, and operation for strangulated hernia in rural Africa. BMJ. 1984;289(6437):92-93.

5. Aboyeji AP, Ijaiya MA, Fawole AA. Maternal mortality in a Nigerian teaching hospital - a continuing tragedy. Tropical Doctor. 2007;37(2): 83-85.

6. Ouédraogo CM, Ouédraogo A, Ouattara A, Lankoandé J. [Cesarean deliveries in a district hospital in Ouagadougou. Epidemiological, clinical, and prognostic study of 3381 cases]. Med Sante Trop. 2015;25(2): 194-199.

7. Abiodun OM, Balogun OR. A review of caesarean sections associated with perinatal mortality at the University of Ilorin teaching hospital, Ilorin, Nigeria. Niger J Clin Pract. 2009;12(3):248-251.

8. Merali HS, Lipsitz S, Hevelone N, et al. Audit-identified avoidable factors in maternal and perinatal deaths in low resource settings: a systematic review. BMC Pregnancy Childbirth. 2014;14(1):280.

9. Pirkle CM, Dumont A, Zunzunegui M-V. Criterion-based clinical audit to assess quality of obstetrical care in low- and middle-income countries: a systematic review. Int J Qual Health Care. 2011;23(4): 456-463.

10. Adesunkanmi ARK, Faleyimu B. Incidence and aetiological factors of incisional hernia in post-caesarean operations in a Nigerian Hospital. J Obstet Gynaecol. 2003;23(3):258-260.

11. Ali Y. Analysis of caesarean delivery in Jimma Hospital, south-western Ethiopia. East Afr Med J. 1995;72(1):60-63.

12. Amenu D, Belachew T, Araya F. Surgical site infection rate and risk factors among obstetric cases of jimma university specialized Hospital, Southwest Ethiopia. Ethiop J Health Sci. 2011;21(2):91-100. 
13. Ansaloni L, Brundisini R, Morino G, Kiura A, Prospective KA. Prospective, randomized, comparative study of Misgav Ladach versus traditional cesarean section at Nazareth Hospital, Kenya. World J Surg. 2001;25(9):1164-1172.

14. Björklund K, Mutyaba T, Nabunya E, Mirembe F. Incidence of postcesarean infections in relation to HIV status in a setting with limited resources. Acta Obstet Gynecol Scand. 2005;84(10):967-971.

15. Brisibe SF, Ordinioha B, Gbeneolol PK. The effect of hospital infection control policy on the prevalence of surgical site infection in a tertiary hospital in South-South Nigeria. Niger Med J. 2015;56(3): 194-198.

16. Bukar M, Audu BM, Massa AA. Caesarean delivery at the federal medical centre Gombe: a 3-year experience. Niger J Med. 2009;18(2): 179-183.

17. Chilopora G, Pereira C, Kamwendo F, Chimbiri A, Malunga E, Bergström S. Postoperative outcome of caesarean sections and other major emergency obstetric surgery by clinical officers and medical officers in Malawi. Hum Resour Health. 2007;5(1):17.

18. Chu K, Maine R, Trelles M. Cesarean section surgical site infections in sub-Saharan Africa: a multi-country study from Medecins SANS Frontieres. World J Surg. 2015;39(2):350-355.

19. de Nardo P, Gentilotti E, Nguhuni B, et al. Post-caesarean section surgical site infections at a Tanzanian tertiary hospital: a prospective observational study. J Hosp Infect. 2016;93(4):355-359.

20. Ezechi OC, Edet A, Akinlade H, Gab-Okafor CV, Herbertson E. Incidence and risk factors for caesarean wound infection in Lagos Nigeria. BMC Res Notes. 2009;2(1):186.

21. Fesseha N, Getachew A, Hiluf M, Gebrehiwot Y, Bailey P. A national review of cesarean delivery in Ethiopia. Int J Gynaecol Obstet. 2011; 115(1):106-111.

22. Harfouche M, Hosseinipour M, Kaliti S, Wilkinson J. Quality indicators and outcomes of emergency caesarean deliveries at a District-level maternity hospital. Afr J Reprod Health. 2015;19(3):61-67.

23. Jido T, Garba I. Surgical-site infection following cesarean section in Kano, Nigeria. Ann Med Health Sci Res. 2012;2(1):33-36.

24. Johnson AN, Buchmann EJ. Puerperal infection after caesarean section at Chris Hani Baragwanath academic hospital, Johannesburg. S Afr J Obstet Gynaecol. 2012;18(3):90-91.

25. Koigi-Kamau R, Kabare LW, Wanyoike-Gichuhi J. Incidence of wound infection after caesarean delivery in a district hospital in central Kenya. East Afr Med J. 2005;82(7):357-361.

26. Moodliar S, Moodley J, Esterhuizen TM. Complications associated with caesarean delivery in a setting with high HIV prevalence rates. Eur J Obstet Gynecol Reprod Biol. 2007;131(2):138-145.

27. Moran BJ, Busch I, Kirby K. Septic complications of 100 abdominal deliveries in the rural tropics. Trop Doct. 1990;20(1):39-40.

28. Morhason-Bello IO, Oladokun A, Adedokun BO, Obisesan KA, Ojengbede OA, Okuyemi OO. Determinants of post-caesarean wound infection at the University College Hospital Ibadan Nigeria. Niger J Clin Pract. 2009;12(1):1-5.
29. Mpogoro FJ, Mshana SE, Mirambo MM, Kidenya BR, Gumodoka B, Imirzalioglu $\mathrm{C}$. Incidence and predictors of surgical site infections following caesarean sections at Bugando medical centre, Mwanza, Tanzania. Antimicrob Resist Infect Control. 2014;3(1):25.

30. Ojiyi EE, Dike EI, Anolue F, Chukwulebe AE. Appraisal of caesarean section at the IMO state university teaching hospital, Orlu, southeastern Nigeria. Internet J Gynecol Obstet. 2012;16:1-6.

31. Rabiu KA, Adewunmi AA, Akinola OI, Eti AE, Tayo AO. Comparison of maternal and neonatal outcomes following caesarean section in second versus first stage of labour in a tertiary hospital in Nigeria. Niger Postgrad Med J. 2011;18(3):165-171.

32. Saxer F, Widmer A, Fehr J, et al. Benefit of a single preoperative dose of antibiotics in a sub-Saharan district hospital: minimal input, massive impact. Ann Surg. 2009;249(2):322-326.

33. Sekirime WK, Lule JC. Outcome of cesarean section in asymptomatic HIV-1 infection in Kampala, Uganda. J Obstet Gynaecol Res. 2009; 35(4):679-688

34. van Bogaert L-J, Misra A. Peritoneal closure or non-closure at caesarean section. J Obstet Gynaecol. 2009;29(3):217-219.

35. Zvandasara P, Saungweme G, Mlambo JT, Moyo J. Post caesarean section infective morbidity in HIV-positive women at a tertiary training hospital in Zimbabwe. Cent Afr J Med. 2007;53(9-12):43-47.

36. Graham W, Wagaarachchi P, Penney G, McCaw-Binns A, Antwi KY, Hall MH. Criteria for clinical audit of the quality of hospital-based obstetric care in developing countries. Bull World Health Organ. 2000; 78(5):614-620.

37. Souza JP, Gülmezoglu A, Lumbiganon P, et al. Caesarean section without medical indications is associated with an increased risk of adverse short-term maternal outcomes: the 2004-2008 WHO global survey on maternal and perinatal health. BMC Med. 2010;8(1):71.

38. Betrán AP, Ye J, Moller A-B, Zhang J, Gülmezoglu AM, Torloni MR. The increasing trend in caesarean section rates: global, regional and national estimates: 1990-2014. PLoS One. 2016;11(2):e0148343.

39. United Nations, Department of Economic and Social Affairs, Population Division (2014). World Urbanization Prospects: The 2014 Revision, Highlights (ST/ESA/SER.A/352).

40. Alexander JW, Solomkin JS, Edwards MJ. Updated recommendations for control of surgical site infections. Ann Surg. 2011;253(6):1082-1093.

41. Mackenzie IZ, Cooke I. What is a reasonable time from decision-todelivery by caesarean section? Evidence from 415 deliveries. BJOG. 2002;109(5):498-504.

42. Wagaarachchi PT, Graham WJ, Penney GC, McCaw-Binns A, Yeboah Antwi K, Hall MH. Holding up a mirror: changing obstetric practice through criterion-based clinical audit in developing countries. Int J Gynaecol Obstet. 2001;74(2):119-130. Discussion 31.

43. Sway A, Kraft K, Wanyoro A, Kilpatrick C, Solomkin J. A review of the burden of infection following cesarean section in sub-Saharan Africa [abstract]. Available from: https://www.escmid.org/escmid_ publications/escmid_elibrary/material $/$ ? $\mathrm{mid}=43093$. Accessed February 25, 2019.
International Journal of Women's Health

\section{Publish your work in this journal}

The International Journal of Women's Health is an international, peerreviewed open-access journal publishing original research, reports, editorials, reviews and commentaries on all aspects of women's healthcare including gynecology, obstetrics, and breast cancer. The manuscript management system is completely online and includes

\section{Dovepress}

a very quick and fair peer-review system, which is all easy to use. Visit http://www.dovepress.com/testimonials.php to read real quotes from published authors. 